\title{
Leucoagaricus gongylophorus uses leaf-cutting ants to vector proteolytic enzymes towards new plant substrate
}

\author{
Pepijn W Kooij ${ }^{1}$, Adelina Rogowska-Wrzesinska ${ }^{2}$, Daniel Hoffmann ${ }^{1}$, Peter Roepstorff ${ }^{2}$, \\ Jacobus J Boomsma ${ }^{1}$ and Morten Schiøtt ${ }^{1}$ \\ ${ }^{1}$ Centre for Social Evolution, Department of Biology, University of Copenhagen, Copenhagen, Denmark \\ and ${ }^{2}$ Protein Research Group, Department of Biochemistry and Molecular Biology, University of Southern \\ Denmark, Odense, Denmark
}

\begin{abstract}
The mutualism between leaf-cutting ants and their fungal symbionts revolves around processing and inoculation of fresh leaf pulp in underground fungus gardens, mediated by ant fecal fluid deposited on the newly added plant substrate. As herbivorous feeding often implies that growth is nitrogen limited, we cloned and sequenced six fungal proteases found in the fecal fluid of the leaf-cutting ant Acromyrmex echinatior and identified them as two metalloendoproteases, two serine proteases and two aspartic proteases. The metalloendoproteases and serine proteases showed significant activity in fecal fluid at $\mathrm{pH}$ values of 5-7, but the aspartic proteases were inactive across a $\mathrm{pH}$ range of 3-10. Protease activity disappeared when the ants were kept on a sugar water diet without fungus. Relative to normal mycelium, both metalloendoproteases, both serine proteases and one aspartic protease were upregulated in the gongylidia, specialized hyphal tips whose only known function is to provide food to the ants. These combined results indicate that the enzymes are derived from the ingested fungal tissues. We infer that the five proteases are likely to accelerate protein extraction from plant cells in the leaf pulp that the ants add to the fungus garden, but regulatory functions such as activation of proenzymes are also possible, particularly for the aspartic proteases that were present but without showing activity. The proteases had high sequence similarities to proteolytic enzymes of phytopathogenic fungi, consistent with previous indications of convergent evolution of decomposition enzymes in attine ant fungal symbionts and phytopathogenic fungi.
\end{abstract}

The ISME Journal (2014) 8, 1032-1040; doi:10.1038/ismej.2013.231; published online 9 January 2014

Subject Category: Microbe-microbe and microbe-host interactions

Keywords: Acromyrmex echinatior, nutrition; mutualism; phytopathogens; proteases

\section{Introduction}

Obligate symbioses are characterized by high degrees of partner commitment and functional complementarity (Janzen, 1985). Such interactions normally show only minor remnants of the potential reproductive conflicts that needed to be overcome when these partnerships evolved, allowing them to ultimately become single adaptive units with organismal properties (Queller and Strassmann, 2009; Boomsma, 2013). Such high levels of interdependency are most characteristic for endosymbioses where the symbiont lives in cells or tissues of the host, but may also occur in ectosymbioses like the

Correspondence: PW Kooij or M Schiøtt, Centre for Social Evolution, Department of Biology, University of Copenhagen, Universitetsparken 15, Copenhagen DK-2100, Denmark.

E-mail: pkooij@bio.ku.dk or mschiott@bio.ku.dk

Received 16 August 2013; revised 26 November 2013; accepted 27

November 2013; published online 9 January 2014 eusocial fungus-farming mutualisms of ants and termites where the fungus gardens are ectosymbionts for the individual ants but endosymbionts for the colony (Poulsen and Boomsma, 2005; Aanen et al., 2009). We are intuitively inclined to consider the insect colony as the active farming host and the fungus gardens as passive crops, but the contention that fungal clones have contracted ant families to propagate them across generations appears to be equally valid, especially in the attine ants where the fungal symbiont is vertically transmitted (Poulsen and Boomsma, 2005).

In terms of biomass conversion efficiency, the functional complementarity between attine ants and their fungus garden symbionts achieved spectacular progression, moving from initial stages of ant-driven litter-based decomposition farming that evolved 50 million years ago (MYA) to advanced farming of irreversibly domesticated crop fungi 20 MYA (Mueller et al., 1998; Schultz and Brady, 2008; Mehdiabadi and Schultz, 2010), culminating in 
aggressive herbivorous leaf-cutting farming 10 MYA (De Fine Licht et al., 2010; Schiøtt et al., 2010). Particularly, the latter transition allowed the ants to evolve much larger and complex societies (Mueller et al., 1998; Villesen et al., 2002; Schultz and Brady, 2008; Fernandez-Marin et al., 2009; Mehdiabadi and Schultz, 2010) after they had managed to overcome a series of challenges that are associated with a herbivorous life-style (Schiøtt et al., 2008, 2010; De Fine Licht et al., 2010, 2013). Although depending on live vegetation rather than dead leaf litter undoubtedly implied better access to the proteins that normally limit insect growth, an almost exclusive fungal diet is generally poorer in protein than the carnivorous diets of many hunter-gatherer species in the Myrmicinae subfamily of ants (Davidson, 2004). Hosts and symbionts can thus be assumed to have been under consistent selection to maximize protein yield as this will determine colony growth rate and the production of winged virgin queens that transmit both their own genes and clonal copies of the fungal symbiont to future generations.

Specialized foraging on live plant material as growth substrate for the fungal symbiont Leucoagaricus gongylophorus implies that leaf-cutting ants are major herbivores in the Neo(sub)tropics with substantial roles in recycling nitrogen and phosphorus (Fowler et al., 1989). A recent study has confirmed that the leaf-cutting fungus-farming mutualism is likely to be nitrogen limited as Atta fungus gardens harbour substantial levels of nitrogen-fixing bacteria (Pinto-Tomás et al., 2009). Studies on the other genus of leaf-cutting ants, Acromyrmex, have shown that the fungal symbiont uses the ants to vector pectinases and a laccase from the most productive middle layers of fungus gardens to the top where they are most useful for the symbiosis but where fungal biomass to produce these enzymes is in short supply (Schiøtt et al., 2010; De Fine Licht et al., 2013). The fungal gongylidia, special hyphal tips produced only to feed the ants and their brood (Bass and Cherrett, 1995), are instrumental in this process as they upregulate the expression of genes producing these enzymes (Schiøtt et al., 2010; De Fine Licht et al., 2013). These studies indicate that the fungal symbiont uses the ants for vector enzymes for the neutralization of phenolic compounds (laccase) and for loosening up the cell wall matrix (pectinases) to new garden sections. However, whether these initial decomposition steps are followed by a similar boost in protease activity to decompose intracellular proteins has remained unknown.

The ants process freshly cut leaf fragments into a mass of leaf pulp while mixing it with droplets of fecal fluid and subsequently deposit the new substrate on fungal ridges in the top of the garden where they inoculate it with small tufts of mycelium from the older part of the garden (Weber, 1966). In the 1970s, leaf-cutting ant fecal fluid was shown to contain active proteases (Martin, 1970, 1974;
Martin and Martin, 1970a, b, 1971) with similar chemical properties as enzymes originating from the fungal symbiont (Boyd and Martin, 1975a, b), and recent work has shown that fungus garden endo-protease activity in evolutionarily derived leaf-cutting ants is much higher than in sister ant lineages that do not use fresh leaves to make their gardens grow (De Fine Licht et al., 2010), activity that could subsequently be assigned to metalloproteases and serine proteases (Semenova et al., 2011).

Recently, we obtained the proteome of Acromyrmex echinatior fecal fluid and were able to identify 33 proteins. Among these were seven pectinases (Schiøtt et al., 2010), one laccase (De Fine Licht et al., 2013) and seven proteases. Only a single of these proteases is known to be produced by the ants, whereas the other six are contributed by the fungal symbiont. We hypothesized that a number of these proteases might serve to either process the intracellular proteins of freshly opened plant cells or to assist in the breakdown of secondary plant defences (Christeller et al., 1992; Mercado-Flores et al., 2003; Ievleva et al., 2006). The latter is a distinct possibility as plants are known to use protease inhibitors to counteract the harmful effect of proteases produced by phytopathogic fungi and to generally decrease the digestibility of their tissues to discourage herbivores (Habib and Fazili, 2007). The objectives of the present study were to: (1) measure the specific protease activity in fecal fluid of gardening A. echinatior workers, (2) confirm that they are derived from the fungal symbiont and have different expression levels and $\mathrm{pH}$ optima, (3) assess the extent to which the expression of genes coding for these enzymes was enhanced in the fungal gongylidia, as would be expected when vectoring these enzymes to the top of fungus gardens is a specific adaptation of the symbiosis and (4) discuss the implications of our results for understanding the co-adaptations between partners that has allowed this symbiosis to evolve its substantial ecological footprint in the Neo(sub)tropics.

\section{Materials and methods}

Biological material

We used seven colonies of A. echinatior (Ae263, Ae280, Ae322, Ae332, Ae335, Ae349 and Ae370), collected in and around Gamboa, Panama, between 2004 and 2007 and kept in rearing facilities in Copenhagen under controlled conditions of ca $25{ }^{\circ} \mathrm{C}$ and ca $70 \%$ humidity, where they were fed twice a week with fresh bramble leaves, apple pieces and dry rice. Fecal fluid was obtained by gently squeezing the abdomen of large workers with a forceps on a microscope slide. Each fecal droplet was then mixed with $0.5 \mu \mathrm{l}$ of demineralized water, collected with a micropipette and stored in an Eppendorf tube on ice. Sixty droplets from five colonies each (Ae263, Ae280, Ae322, 
Ae332 and Ae349) were collected this way, pooled per colony and diluted with demineralized water to a final volume of $250 \mu \mathrm{l}$.

For the gene expression measurements, gongylidia clusters (staphylae) and normal mycelium were collected separately under a stereomicroscope at $\times 40$ magnification from each of five colonies (Ae263, Ae280, Ae322, Ae335 and Ae370) in $2 \mathrm{ml}$ Eppendorf tubes floating in liquid nitrogen. After collecting approximately $100 \mu \mathrm{l}$ for each type of tissue, samples were stored at $-80{ }^{\circ} \mathrm{C}$ for subsequent RNA extraction.

\section{Protein identification and gene cloning}

SDS-polyacrylamide gel electrophoresis and mass spectrometry were performed as described previously (Schiøtt et al., 2010; De Fine Licht et al., 2013). RNA extraction from the fungal symbiont, followed by cDNA construction, was done as given in Schiøtt et al. (2010). Aspartic protease 2 (AspII), metallopeptidase 1 (MetI), serine protease 1 (SerI) and serine protease 2 (SerII) were initially identified by PCR amplification from cDNA using degenerate primers constructed from the mass spectrometry data using the PCR scheme: one cycle of $95{ }^{\circ} \mathrm{C}$ for $5 \mathrm{~min}, 35$ cycles of $94{ }^{\circ} \mathrm{C}$ for $20 \mathrm{~s}, 50{ }^{\circ} \mathrm{C}$ for $30 \mathrm{~s}$ and $72{ }^{\circ} \mathrm{C}$ for $2 \mathrm{~min}$, and ending with one cycle of $72{ }^{\circ} \mathrm{C}$ for $7 \mathrm{~min}$. Aspartic protease 1 (AspI) and metallopeptidase 2 (MetII) were identified at a later stage by a Blast search of the ca 100x coverage A. echinatior genome (Nygaard et al., 2011) and a low coverage genome sequence of the $A$. echinatior fungal symbiont (De Fine Licht et al., 2013) using the mass spectrometry data as queries. Sequencing of full-length gene transcripts was done using a RACE (Rapid Amplification of cDNA Ends) strategy. $3^{\prime}$ - and 5'-RACE libraries were made from ca $1 \mu \mathrm{g}$ of purified RNA with the SMART RACE cDNA kit (Clontech, Mountain View, CA, USA), and gene sequences were PCR amplified from these libraries using specific primers designed from the PCRamplified gene fragments (AspII, MetI, SerI and SerII) or BLAST search-identified sequence reads (AspI and MetII) along with the primers enclosed in the SMART RACE cDNA kit. In some cases, the $5^{\prime}$-RACE had to be done in several steps to get a full transcript sequence. The following PCR scheme was used in the RACE experiments: one cycle of $95^{\circ} \mathrm{C}$ for 5 min, 10 cycles of $94^{\circ} \mathrm{C}$ for $20 \mathrm{~s}, 72^{\circ} \mathrm{C}$ for $30 \mathrm{~s}$ (with a decrease in temperature of $0.5^{\circ} \mathrm{C}$ in every cycle) and $72{ }^{\circ} \mathrm{C}$ for $2 \mathrm{~min}$, followed by 35 cycles of $94{ }^{\circ} \mathrm{C}$ for $20 \mathrm{~s}, 67^{\circ} \mathrm{C}$ for $30 \mathrm{~s}$ and $72{ }^{\circ} \mathrm{C}$ for $2 \mathrm{~min}$, and ending with one cycle of $72{ }^{\circ} \mathrm{C}$ for $7 \mathrm{~min}$. All PCR products were cloned in pCR4-TOPO using the TOPO TA cloning method (Invitrogen, Carlsbad, CA, USA) and sequenced at Eurofins MWG Operon (Ebersberg, Germany). Gene sequences are deposited in GenBank with accession numbers KF571927KF571932. Primer sequences for cloning of the genes are provided in Supplementary Table 1.

\section{Enzyme assays}

Protease activity was measured for four different protease inhibitors and two controls (without inhibitors, one of which incubated and the other not incubated) at eight different $\mathrm{pH}$ levels. The inhibitors used in the experiment were $5 \mathrm{~mm}$ 1,10-phenanthroline to inhibit metalloendoproteases, $2 \mu \mathrm{M}$ pepstatin to inhibit aspartic proteases, $10 \mathrm{~mm}$ phenylmethylsulfonyl fluoride to inhibit serine proteases and $10 \mu \mathrm{M}$ trans-epoxysuccinyl-Lleucylamido(4-guanidino)butane to inhibit cysteine proteases. In the assay, $4 \mu \mathrm{l}$ of the diluted fecal fluid was mixed with $1 \mu \mathrm{l}$ of inhibitor or distilled demineralized water and incubated on ice for $1 \mathrm{~h}$. Next, $35 \mu \mathrm{l}$ of $0.1 \mathrm{~m}$ Britton Robinson buffer (Britton and Robinson, 1931) with $2 \%$ azoalbumin was added and the mix was incubated at $30^{\circ} \mathrm{C}$ for $1 \mathrm{~h}$. For the blank control (not incubated), the azoalbumin mix was added at the last moment without incubation to prevent any protease activity to occur. To stop the activity of the proteases, $120 \mu \mathrm{l}$ of $10 \%$ trichloroacetic acid was added, after which the mix was vortexed and incubated for $15 \mathrm{~min}$ before centrifugation for $5 \mathrm{~min}$ at $8000 \mathrm{~g}$. The supernatant $(86 \mu \mathrm{l})$ was added to $100 \mu \mathrm{l}$ of freshly prepared $1 \mathrm{M}$ $\mathrm{NaOH}$ on a 96-well cell culture plate.

Absorbance was measured at $440 \mathrm{~nm}$ on a Versamax ELISA microplate reader (Molecular Devices, Sunnyvale, CA, USA) and scored after subtracting the corresponding blank-control measurements to correct for background absorbance. To find the enzyme activity in each of the four protease classes, measurements obtained with specific inhibitors for each protease class were subtracted from the total protease activity in identical assays without addition of inhibitors. Protease activity was defined as the amount of enzyme required to cause a unit increase at $440 \mathrm{~nm}$ across a $1 \mathrm{~cm}$ path length (Sarath et al., 2001). The number of units of protease activity data was plotted and analysed with R (R Core Team, 2013), using Linear Mixed-Effects Models ('Ime'; Pinheiro et al., 2013), with colony as random factor, and generating $P$-values with General Linear Hypotheses ('glht') in the Simultaneous Inference in General Parametric Models package 'multcomp' (Hothorn et al., 2008).

For measuring protease activity in control ants, 100-200 workers of the colonies Ae322, Ae332 and Ae349 were transferred to subcolonies with no access to fungus garden material, but with an ad libitum diet of $10 \%$ sucrose and bramble leaves. After ca 2 weeks, protease activity was measured in pooled samples of fecal droplets from two ants for each colony at $\mathrm{pH} 6$ in three replicates per colony.

\section{Quantitative real-time PCR}

Primers for the six different genes (Supplementary Table 2) were designed by matching the obtained cDNA sequences to a database of a partially sequenced genome of the A. echinatior fungal 
symbiont (De Fine Licht et al., 2013) using BLASTn to identify intron and exon sequences. Primers were designed to span an intron to avoid amplification of genomic DNA. The quantitative PCRs (qPCRs) were run on an Mx3000P QPCR System (Agilent, Santa Clara, CA, USA) in $20 \mu \mathrm{l}$ reactions $(0.5 \mu \mathrm{l}$ cDNA, $10 \mu \mathrm{l} 2 \times$ SYBR Premix Ex Taq (TaKaRa Bio Inc., Otsu, Japan) and $0.4 \mu \mathrm{l}$ of each primer $(10 \mu \mathrm{M}))$ with the following PCR conditions: one cycle of $95^{\circ} \mathrm{C}$ for $2 \mathrm{~min}$, followed by 40 cycles of $95^{\circ} \mathrm{C}$ for $30 \mathrm{~s}, 55^{\circ} \mathrm{C}$ (AspI, AspII, MetII, SerI, SerII and elongation factor $1-\alpha(E F 1 \alpha))$ or $57^{\circ} \mathrm{C}$ (MetI, glyceraldehyde 3-phosphate dehydrogenase (GAPDH), ubiquitin (Ubc)) for $30 \mathrm{~s}$ and $72{ }^{\circ} \mathrm{C}$ for $30 \mathrm{~s}$, and ending with a melting curve cycle of $95{ }^{\circ} \mathrm{C}$ for $30 \mathrm{~s}, 55^{\circ} \mathrm{C}$ or $57^{\circ} \mathrm{C}$ for $30 \mathrm{~s}$ and $95^{\circ} \mathrm{C}$ for $30 \mathrm{~s}$.

For each of the 10 samples (one gongylidia and one mycelium sample from five colonies), three technical qPCR replicates were done for nine genes: three housekeeping genes (GAPDH, Ubc and EF1 $\alpha$ ) and six target genes (MetI, MetII, AspI, AspII, SerI and SerII). All Ct values from the reverse transcription qPCR analysis were analysed in $\mathrm{R}$ with packages 'ReadqPCR' (Perkins and Kohl, 2011) and 'NormqPCR' (Kohl and Perkins, 2011) using averages across the three technical replicates. Stability of housekeeping genes was assessed across the entire data set, which showed that GAPDH and $U b c$ were more stable than $E F 1 \alpha$, so the latter gene was discarded in the further analyses. GAPDH and $U b c$ were then used to calculate the normalized expression $\left(2^{\Delta \mathrm{Ct}}\right)$ of the target genes in gongylidia and mycelium. Values of $2^{-\Delta \Delta \mathrm{Ct}}$ (Livak and Schmittgen, 2001) for each gene subsequently produced estimates of fold changes in relative gene expression between gongylidia and mycelium. This sequence of procedures allowed us to identify genes with significantly different expression levels and to obtain estimates of their normalized and relative expression.

\section{Results}

The mass spectrometry data of fecal fluid proteins (Table 1) described previously (Schiøtt et al., 2010) allowed us to clone and sequence six protease genes encoded by the fungal symbiont genome, and to identify an ant-encoded protease (EGI65848) belonging to a family of M14 carboxypeptidases, which is significantly expanded in the genome of $A$. echinatior (Nygaard et al., 2011). Comparison with the MEROPS database release 9.8 (http://merops.sanger. ac.uk/; Rawlings et al., 2012; Supplementary Table 3) showed that all six proteases (AspI, AspII, MetI, MetII, SerI and SerII) were similar to peptidases known from other fungi; AspI with saccharopepsin (A01.018) from Laccaria bicolor (78.57\%, $E$-value $\left.=1.10 \mathrm{e}^{-142}\right) ; \quad$ AspII with polyporopepsin (A01.019) from L. bicolor $(71.60 \%, E$-value $=1.80$ $\left.\mathrm{e}^{-125}\right)$; MetI with peptidyl-Lys metallopeptidase
(M35.004) from Pleurotus ostreatus (56.55\%, $E$-value $=1.50 \mathrm{e}^{-53}$ ); MetII with peptidyl-Lys metallopeptidase (M35.004) from P. ostreatus (69.23\%, $E$-value $=2.60 \mathrm{e}^{-42}$ ); SerI with an unassigned peptidase from the S8A subfamily from L. bicolor $\left(61.28 \%, E\right.$-value $\left.=6.90 \mathrm{e}^{-111}\right)$; SerII with grifolisin (S53.010) from L. bicolor (66.67\%, $E$-value $\left.=4.40 \mathrm{e}^{-136}\right)$.

To test the overall protease activity in the ant fecal fluid and to determine whether the fungus garden is responsible for this activity, protease activity was measured in fecal droplets of worker ants taken directly from their colonies and from purged ants that had been kept on sugar water and bramble leaves for ca 2 weeks with no access to fungal garden material. This showed that protease activity is present in fecal fluid when the ants have their normal diet, but disappears almost completely when the ants are deprived of fungus garden material $\left(t_{17}=14.8972, P<0.0001\right)$, indicating that the protease activity in the ant fecal fluid is caused by ingested proteases from the fungal symbiont and not by proteases produced by the ants themselves (Figure 1).

Next, we tested the activity of the four main types of proteases using different inhibitors specifically targeted at each category of proteases: metalloendoproteases, serine proteases, aspartic proteases and cysteine proteases. Only the metalloendoproteases and serine proteases had significant activities, with respective peaks at $\mathrm{pH} 6(z=-10.824, P<0.0001)$ and pH $7(z=4.654, P<0.0001)$ and serine protease activity also being significantly enhanced at $\mathrm{pH} 6$ $(z=2.004, P<0.05)$, consistent with fecal fluid also having $\mathrm{pH} 6$ (Figure 2). In contrast to serine proteases, metalloendoproteases were active at a very broad range of $\mathrm{pH}$ values and retained activities up to $\mathrm{pH}$ 10. We found no activity for aspartic proteases (present in fecal fluid), and cysteine proteases (absent in fecal fluid).

Relative changes in gene expression in gongylidia versus mycelium (fold-changes: $2^{-\Delta \Delta \mathrm{Ct}}$ ) showed that the expression of five out of the six fungal protease genes was upregulated in the gongylidia compared with the mycelium (Figure 3a): peptidyl-Lys metallopeptidase I and II (MetI and MetII; $z=-3.979$, $P=0.00004 ; z=-20.010, P=0.00001)$, saccharopepsin (AspI; $z=-3.946, P=0.00004)$, subtilisin (SerI; $z=-8.927, P=0.00001$ ) and grifolisin (SerII; $Z=-9.041, P=0.00001)$, whereas the expression of polyporopepsin (AspII) remained unchanged $(\mathrm{z}=2.580, P=0.99492)$. This is consistent with all but one of these fungal proteases having their main function after being ingested by the ants, that is, after they pass the ant guts unharmed to be deposited with the fecal fluid.

Plotting relative gene expression (fold change in gongylidia versus mycelium) as a function of normalized gene expression in the gongylidia (that is, expression relative to housekeeping genes; Figure $3 \mathrm{~b}$ ) showed proportionality for four of the 
Table 1 Peptide sequences of proteases in fecal fluid of Aechinatior and corresponding molecular weights (Da) of full-length proteins

\begin{tabular}{|c|c|c|c|}
\hline Protein & Mass spectrometry data & Sequence data & $M W(D a)$ \\
\hline \multirow[t]{3}{*}{ Aspartic protease 1} & DENDGGEATFGGJNPSSYR & DENDGGEATFGGINPSSYR & 44788 \\
\hline & NAYWEV & NAYWEV & \\
\hline & YFTVYDJGR & YFTVYDLGR & \\
\hline \multirow[t]{5}{*}{ Aspartic protease 2} & FTGAJNFTPR & FTGALNFTPR & 43158 \\
\hline & SSGFEGTDGJJGJGPVDJTR & SSGFEGTDGILGIGPVDLTR & \\
\hline & GTJSPAVNSJVPTVTDNJFSSGR & GTLSPAVNSLVPTVTDNLFSSGR & \\
\hline & TSTSPSSJFWGJNQSVR & TSTSPSSLFWGLNQSVR & \\
\hline & VJDNNTGJJR & VLDNNTGLLR & \\
\hline \multirow[t]{2}{*}{ Metallopeptidase 1} & TYASNAATYJSSHSSSSTR & TYASNAATYLSSHSSSSTR & 37207 \\
\hline & YTTWFGTYTSAR & YTTWFGTYTSAR & \\
\hline Metallopeptidase 2 & TYASNAJJYJR & TYASNALIYLR & 37511 \\
\hline \multirow[t]{2}{*}{ Serine protease 1} & AWAGJHFAVAAGNDNR & AADAGLHFAVAAGNDNR & 50114 \\
\hline & GSDGSGSTSDVJAGVQWAAR & GSDGSGSTSDVIAGVQWAAR & \\
\hline \multirow[t]{8}{*}{ Serine protease 2} & ADJQTFFR & ADLQTFFR & 63388 \\
\hline & AGYJDEFANR & AGYLDEFANR & \\
\hline & AJYNTVNYVPSQTSR & ALYNTVNYVPSQTSR & \\
\hline & DGJGVAGYJDEFANR & NGLGVAGYLDEFANR & \\
\hline & GVAGYJDEFANR & GVAGYLDEFANR & \\
\hline & GSVGGTSASSPTVAGVFAJJNDFR & GSVGGTSASSPTVAGVFALLNDFR & \\
\hline & FRPDAAGSSFTTVR & FRPDAAGSSFTTVR & \\
\hline & YFSTPSYQSAAVSR & YFSTPSYQSAAVSR & \\
\hline Carboxypeptidase A (EGI65848) & QNNPGVFFESGJHAR & QNNPGVFFESGIHAR & 46943 \\
\hline
\end{tabular}

The letter J symbolizes the amino acids leucin and isoleucin, which have the same molecular mass and are therefore indiscernible by mass spectrometry. The single discrepancy between mass spectrometry data and sequence data (letters $\mathrm{D}$ and $\mathrm{N}$ in bold) may have been caused by deamination of asparagine into aspartic acid.

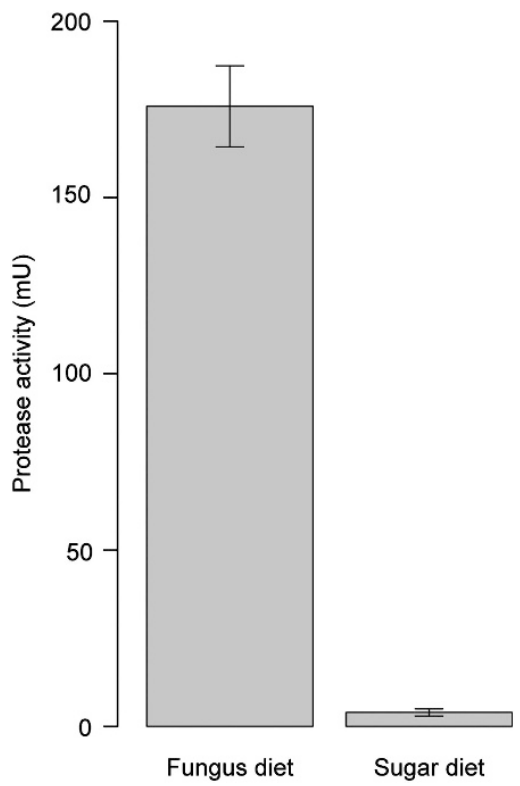

Figure 1 Enzyme activity in milliunits of proteases (mU) in fecal fluid of workers of the leaf-cutting ant $A$. echinatior kept on natural fungus-garden-diet and on a diet of only sugar water and possibly plant sap as control $\left(t_{17}=14.8972, P<0.0001\right)$. Whiskers are s.e. of the mean.

proteases (saccharopepsin, subtilisin, grifolisin and polyporopepsin). However, the two metalloendoproteases deviated from the 1:1 proportionality represented by the diagonal in Figure $3 \mathrm{~b}$. One of them (MetII) combined a fairly low normalized expression (Supplementary Table 4) with a $17 x$ upregulation in

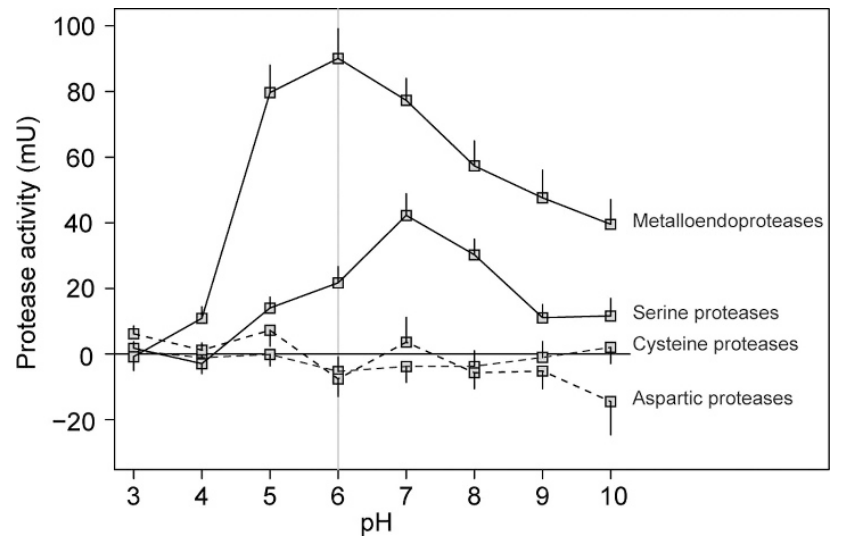

Figure 2 Activity of metalloendoproteases, serine proteases, aspartic proteases and cysteine proteases in milliunits (mU). Both metalloendoproteases $(z=10.824, P<0.0001)$ and serine proteases $(z=2.004, P<0.05)$ showed significantly enhanced activity at $\mathrm{pH} 6$ relative to the zero baseline. Serine proteases had their peak activity at $\mathrm{pH} 7(z=4.654, P<0.0001)$ and activities of metalloendoproteases at $\mathrm{pH}$ levels $>7$ remained equally significant as those at $\mathrm{pH} 6$. Whiskers are s.e. of the mean.

gongylidia, and the other (MetI) combined a high normalized expression with a relatively low $5 \mathrm{x}$ fold upregulation in gongylidia. This implies that the expression of MetII is much more gongylidia specific than the expression of MetI, which is apparently also needed in high quantities in the undifferentiated mycelium. It also appeared that the single non-differentially expressed protease ( $A s p I I)$ had a low normalized expression level (Figure $3 \mathrm{~b}$ ), indicating that it may not have a very important role 

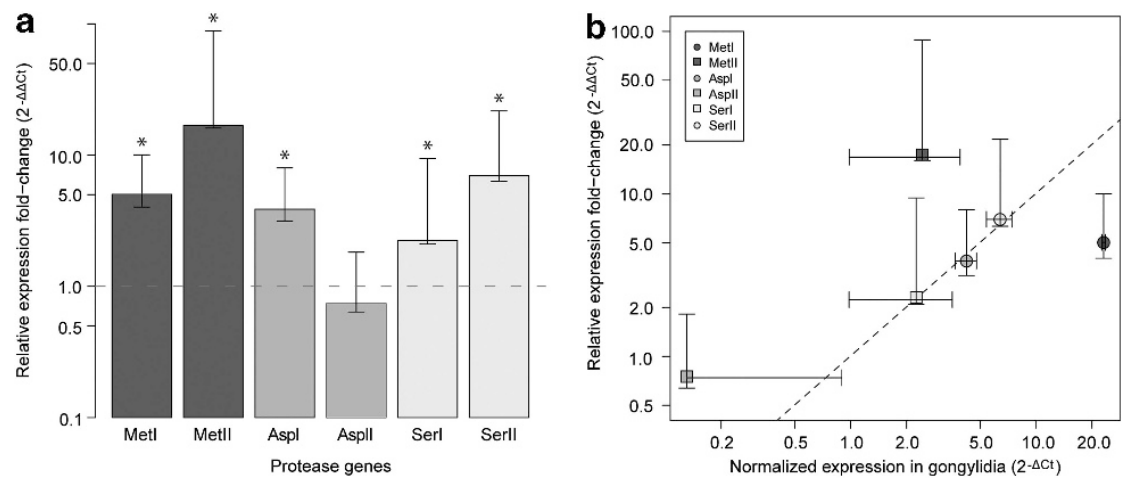

Figure 3 Average relative gene expression (fold change) across gongylidia collected from fungus gardens of five colonies of A. echinatior: dark grey $=$ metalloendoproteases, grey $=$ aspartic proteases, light grey $=$ serine proteases. (a) Relative expression fold changes (mean \pm s.e.) in gongylidia compared with mycelium, with the dashed horizontal line representing no change in expression. Target genes were significantly upregulated in the gongylidia $(P=0.00004,0.00001,0.00004,0.99492,0.00001$ and 0.00001 for $M e t I$, MetII, AspI, AspII, SerI and SerII, respectively, marked with asterisk (*)), except for polyporopepsin (AspII). (b) Relative expression foldchange plotted against gene expression normalized for the housekeeping genes GAPDH and Ubc (means \pm s.e.). The three upregulated serine (SerI and SerII) and aspartic ( $A s p I)$ proteases had fold-changes proportional to normalized gene expression (being very close to the dashed line diagonal), but peptidyl-Lys metallopeptidase I (MetI) combined a high normalized gene expression with a relatively low gene fold-change, and peptidyl-Lys metallopeptidase II (MetII) combined a low normalized gene expression with a relatively high gene foldchange.

under normal conditions, but might have an unknown adaptive function under specific field conditions that did not apply to our laboratory colonies.

\section{Discussion}

In the present study, we used mass spectrometry to identify seven proteases in the fecal fluid of A. echinatior leaf-cutting ants. For all but one of these we could exclude that they are produced by the ants, because we have a high-quality reference genome for the ants (Nygaard et al., 2011), to which only one protease matched, and a poorly assembled genome for the fungal symbiont (De Fine Licht et al., 2013) to which the remaining six sequences matched. Our protease assays showed both metalloendoprotease activity and serine protease activity in the ant fecal fluid, but when we deprived the ants of their fungal symbiont by giving them a diet of sugar water and bramble leaves, essentially all protease activity disappeared. We further showed that five out of the six protease genes were overexpressed in the fungal gongylidia that the ants eat. In combination, the results strongly suggest that these proteases mostly belong to a distinct but restricted group of proteins that have been selected to be ingested by the ants for the sole purpose of being passed on to the fecal fluid where they provide functional mutualistic benefits for the farming symbiosis. The most parsimonious hypothesis to explain this remarkable phenomenon is that the stationary fungus uses the ants to vector crucial enzymes produced in the central parts of the garden, where the ratio between fungal biomass and remaining substrate allows high gongylidia production, to the upper parts of the garden, where an abundance of new substrate is available but as yet without much hyphal growth. These findings and interpretations are consistent with earlier results obtained for seven pectinases (Schiøtt et al., 2010) and a laccase enzyme (De Fine Licht et al., 2013). It remains possible that the ingested fungal enzymes also interact with unknown other compounds in the ant gut, produced either by the ants or their microbiome, but such additional complexities appear unnecessary to explain our current or previous results obtained for other enzymes in the gongylidia and fecal fluid (Rønhede et al., 2004; Schiøtt et al., 2010; De Fine Licht et al., 2013).

It remains to be seen whether the proteases that we identified may also have functions that are restricted to the gongylidia. If that would be the case, the non-adaptive null hypothesis would be that finding them in the fecal fluid may merely imply that digestion was incomplete, but this seems unlikely given that SDS-polyacrylamide gel electrophoresis-banding patterns of fecal fluid were always consistent, showing a very specific subset of proteins that escape digestion (Schiøtt et al., 2010). Together with our previous work (Schiøtt et al., 2010; De Fine Licht et al., 2013), we have now shown that 12 of the 14 identified fungal pectinase, laccase and protease enzymes in the A. echinatior fecal fluid have upregulated gene expression in the gongylidia, which we believe underlines the key significance of these special hyphal tips as fungal organs mediating a series of symbiotic adaptations.

As it appears, the main function of the fecal fluid proteases is enhanced digestion of the most valuable nitrogen-containing molecules of the fresh plant material harvested by the leaf-cutting ants. PeptidylLys metallopeptidases (MetI and MetII) and serine carboxyl-peptidases (SerII) have been suggested to be involved in the extraction of nutrients from extracellular proteins (Heck, 2012; Oda, 2012). As both MetI, MetII and SerII were active in the fecal 
fluid (Figure 2) and upregulated in the gongylidia (Figure 3), it seems reasonable to hypothesize that these enzymes increase nitrogen extraction from the chewed-up leaf pulp after other enzymes such as the pectinases (Schiøtt et al., 2010) have partially broken down the cell walls. The other active serine protease, subtilisin, is structurally similar to several unassigned fungal proteases in the subfamily S8A (Supplementary Table 3). Most of the matches in protein databases for this enzyme were proteases from general pathogenic or phytopathogenic fungi. This finding is intriguing, because most of the subtilisins in subfamily S8A are part of a large gene-family expansion in Angiosperms with functional roles in seed or fruit development or manipulating cell walls in response to changes in biotic and abiotic factors (Schaller, 2012; Schaller et al., 2012).

Although subtilisins likely have defensive functions in plants, other studies have shown that subtilisins have important aggressive functions in saprotrophs, phytopathogens and other infectious pathogens (Sreedhar et al., 1999; Dunaevskii et al., 2006; Ievleva et al., 2006; Bryant et al., 2009; Li et al., 2010). One explanation for this could be that using proteins very similar to those present in the hosts may allow pathogens to avoid detection by immune defences, a phenomenon referred to as molecular mimicry (Elde and Malik, 2009; Armijos Jaramillo et al., 2013). Although the fungal symbionts of leaf-cutting ants hardly face any active immune defence in the severed plant material that the ants bring in, they will be challenged by substantial amounts of secondary (defensive) compounds, similar to any functional insect herbivores whose digestive systems need to cope with plant defences that decrease digestibility (Chen, 2008). Gongylidial subtilisin might therefore have some role in the penetration and digestion of newly harvested plant material, consistent with serine protease activity being also high in the gardens of other higher attine ants. Panamanian representatives of the genera Trachymyrmex and Sericomyrmex that readily use soft fresh leaves as substrate in the laboratory tend to have very high levels of serine protease activity in their fungus gardens, whereas these levels tend to be low in attine ant species that do not or only reluctantly use fresh leaves as fungal substrate (Semenova et al., 2011, P. Kooij and M. Schiøtt, unpublished observations).

We found two aspartic proteases in the fecal fluid, but none of them showed activity (Figure 2), even though one of them, saccharopepsin, was upregulated in the gongylidia when compared with mycelium (Figure 3). This suggests that this protein has a function, either for the gongylidia or after ingestion by the ants. Saccharopepsin is known to be important in the activation of yeast vacuolar hydrolases (Parr et al., 2007). This could explain the abundance of this enzyme in the gongylidia as they always have a large vacuole, but it does not explain why this protease is passed on to the fecal fluid. As non-upregulated polyporopepsin is also found in fecal fluid, it might be that these proteases cleave very specific target sequences so they would not show activity in our general activity assays. Possible target sequences could be other fungal enzymes that are produced as inactive precursors (zymogens or proenzymes), which are subsequently activated when regulatory proteases cleave off part of the precursor amino-acid chain. Such an activation mechanism would be particularly appropriate for abundant plant-degrading enzymes that are also harmful to the fungus garden but not to the ants. These enzymes could then be produced in large quantities in the gongylidia, but only be activated in the ant gut to be mixed with the plant substrate via fecal fluid before the fungal hyphae are inoculated.

The possibility of leaf-cutting ant fungi having independently evolved adaptations reminiscent of phytopathogens is intriguing, so it is of interest to briefly evaluate recent studies addressing evolutionary arms-races between phytopathogens and their host plants (Misas-Villamil and van der Hoorn, 2008). Also here, metalloproteases appear to have a role in the breakdown of cell wall-stabilizing proteins (Rauscher et al., 1995) and in targeting specific plant resistance proteins (Xia, 2004). Among serine proteases, trypsins appear to be most prevalent in phytopathogens, whereas subtilisins are more important in saprotrophs (Dunaevskii et al., 2006, 2008). However, when they occur, subtilisins may have an important role in the breakdown of cell wall structural proteins (Murphy and Walton, 1996), as in infections of Kentucky bluegrass, Poa pratensis (Sreedhar et al., 1999), and in Colletotricum fungi that apparently acquired a subtilisin gene by horizontal transfer from their host plant, encoding a protease which is active during infection (Armijos Jaramillo et al., 2013).

The possible similarities in attine fungal proteases with those of phytopathogens (St Leger et al., 1997) has interesting parallels to our earlier studies on pectinases (Schiøtt et al., 2010), and a laccase (De Fine Licht et al., 2013) in the fecal fluid of A. echinatior ants. Also here, indications of convergent evolution were found, although the evidence remained largely indirect as in the present evaluation of our proteases results. Although many of the molecular mechanisms remain unknown (but see De Fine Licht et al., 2013), it seems beyond doubt that selection pressure on herbivorous leaf-cutting ant fungi must have been largely in the same direction as in unrelated lineages of necrotrophic fungi. The relatively simple fecal fluid proteome (a total of ca 33 identified proteins so far in $A$. echinatior) appears to be a valuable and relatively transparent window through which the molecular adaptations that have shaped fungus farming in the monophyletic clade of the attine ants can be unravelled. 


\section{Conflict of Interest}

The authors declare no conflict of interest.

\section{Acknowledgements}

We thank the Smithsonian Tropical Research Institute (STRI), Panama, for providing logistic support and facilities to work in Gamboa, the Autoridad Nacional del Ambiente y el Mar (ANAM) for permission to sample ant colonies in Panama and to export them to Denmark, and the Danish National Research Foundation for funding (DNRF57).

\section{References}

Aanen DK, De Fine Licht HH, Debets AJM, Kerstes NAG, Hoekstra RF, Boomsma JJ. (2009). High symbiont relatedness stabilizes mutualistic cooperation in fungus-growing termites. Science 326: 1103-1106.

Armijos Jaramillo VD, Vargas WA, Sukno SA, Thon MR. (2013). Horizontal transfer of a subtilisin gene from plants into an ancestor of the plant pathogenic fungal genus Colletotrichum. PLoS One 8: e59078.

Bass M, Cherrett JM. (1995). Fungal hyphae as a source of nutrients for the leaf-cutting ant Atta sexdens. Physiol Entomol 20: 1-6.

Boomsma JJ. (2013). Beyond promiscuity: mate-choice commitments in social breeding. Philos T Roy Soc B 368: 20120050.

Boyd ND, Martin MM. (1975a). Faecal proteinases of the fungus-growing ant, Atta texana: properties, significance and possible origin. Insect Biochem 5: 619-635.

Boyd ND, Martin MM. (1975b). Faecal proteinases of the fungus-growing ant, Atta texana their fungal origin and ecological significanca. J Insect Physiol 21: 1815-1820.

Britton HTS, Robinson RA. (1931). Universal buffer solutions and the dissociation constant of veronal. J Chem Soc 1: 1456-1462.

Bryant MK, Schardl CL, Hesse U, Scott B. (2009). Evolution of a subtilisin-like protease gene family in the grass endophytic fungus Epichloë festucae. BMC Evol Biol 9: 168.

Chen M-S. (2008). Inducible direct plant defense against insect herbivores: a review. Insect Sci 15: 101-114.

Christeller JT, Laing WA, Markwick NP, Burgess E. (1992). Midgut protease activities in 12 phytophagous lepidopteran larvae: dietary and protease inhibitor interactions. Insect Biochem Molec 22: 735-746.

Davidson DW. (2004). Ecological stoichiometry of ants in a New World rain forest. Oecologia 142: 221-231.

De Fine Licht HH, Schiøtt M, Mueller UG, Boomsma JJ. (2010). Evolutionary transitions in enzyme activity of ant fungus gardens. Evolution 64: 2055-2069.

De Fine Licht HH, Schiøtt M, Rogowska-Wrzesinska A, Nygaard S, Roepstorff P, Boomsma JJ. (2013). Laccase detoxification mediates the nutritional alliance between leaf-cutting ants and fungus-garden symbionts. Proc Natl Acad Sci USA 110: 583-587.

Dunaevskii YE, Gruban TN, Belyakova GA, Belozerskii MA. (2006). Extracellular proteinases of filamentous fungi as potential markers of phytopathogenesis. Microbiology+ 75: 649-652.
Dunaevskii YE, Matveeva AR, Fatkhullina GN, Belyakova GA, Kolomiets TM, Kovalenko ED et al. (2008). Extracellular proteases of mycelial fungi as participants of pathogenic process. Russ J Bioorg Chem + 34: 286-289.

Elde NC, Malik HS. (2009). The evolutionary conundrum of pathogen mimicry. Nat Rev Microbiol 7: 787-797.

Fernandez-Marin H, Zimmerman JK, Nash DR, Boomsma JJ, Wcislo WT. (2009). Reduced biological control and enhanced chemical pest management in the evolution of fungus farming in ants. Proc Biol Sic 276: 2263-2269.

Fowler HG, Pagani MI, Da Silva OA, Forti LC, Da Silva VP, De Vasconcelos HL. (1989). A pest is a pest is a pest? The dilemma of Neotropical leaf-cutting ants: keystone taxa of natural ecosystems. Environ Manage 13: 671-675.

Habib H, Fazili KM. (2007). Plant protease inhibitors: a defense strategy in plants. Biotechnol Mol Biol Rev 2: 68-85.

Heck AJR. (2012). Peptidyl-Lys Metalloendopeptidase. In Rawlings ND, Salvesen GS (eds). Handbook of Proteolytic Enzymes Ch 284, Vol. 1. Academic Press: New York, pp 1266-1270.

Hothorn T, Bretz F, Westfall P. (2008). Simultaneous inference in general parametric models. Biometrical $J$ 50: $346-363$.

Ievleva EV, Revina TA, Kudryavtseva NN, Sof'in AV, Valueva TA. (2006). Extracellular proteinases from the phytopathogenic fungus Fusarium culmorum. Appl Biochem Micro + 42: 298-303.

Janzen DH. (1985). The natural history of mutualisms. In: Bucher DH (ed). The Biology of Mutualism. Oxford University Press: New York, pp 40-99.

Kohl M, Perkins J. (2011). NormqPCR: Functions for normalisation of RT-qPCR data. Available at http://www.bioconductor.org/packages/devel/bioc/ html/NormqPCR.html.

Li J, Yu L, Yang J, Dong L, Tian B, Yu Z et al. (2010). New insights into the evolution of subtilisin-like serine protease genes in Pezizomycotina. BMC Evol Biol 10: 68.

Livak KJ, Schmittgen TD. (2001). Analysis of relative gene expression data using real-time quantitative PCR and the 2(-Delta Delta C(T)) Method. Methods 25: 402-408.

Martin JS, Martin MM. (1970a). The presence of protease activity in the rectal fluid of attine ants. I Insect Physiol 16: 227-232.

Martin MM. (1974). Biochemical ecology of the attine ants. Accounts Chem Res 7: 1-5.

Martin MM. (1970). The biochemical basis of the fungusattine ant symbiosis. Science 169: 16-20.

Martin MM, Martin JS. (1970b). The biochemical basis for the symbiosis between the ant, Atta colombica tonsipes and its food fungus. J Insect Physiol 16: 109-119.

Martin MM, Martin JS. (1971). The presence of protease activity in the rectal fluid of primitive attine ants. J Insect Physiol 17: 1897-1906.

Mehdiabadi NJ, Schultz TR. (2010). Natural history and phylogeny of the fungus-farming ants (Hymenoptera: Formicidae: Myrmicinae: Attini). Myrmecol 13: 37-55.

Mercado-Flores Y, Hernández-Rodríguez C, Ruiz-Herrera J, Villa-Tanaca L. (2003). Proteinases and exopeptidases from the phytopathogenic fungus Ustilago maydis. Mycologia 95: 327-339. 
Misas-Villamil JC, van der Hoorn RAL. (2008). Enzymeinhibitor interactions at the plant-pathogen interface. Curr Opin Plant Biol 11: 380-388.

Mueller UG, Rehner SA, Schultz TR. (1998). The evolution of agriculture in ants. Science 281: 2034-2038.

Murphy JM, Walton JD. (1996). Three extracellular proteases from Cochliobolus carbonum: cloning and targeted disruption of ALP1. Mol Plant Microbe In 9: 290-297.

Nygaard S, Zhang G, Schiøtt M, Li C, Wurm Y, Hu H et al. (2011). The genome of the leaf-cutting ant Acromyrmex echinatior suggests key adaptations to advanced social life and fungus farming. Genome Res 21: 1339-1348.

Oda K. (2012). Sedolisin. In Rawlings ND, Salvesen GS (ed). Handbook of Proteolytic Enzymes. Ch 735. Academic Press: New York, pp 3331-3337.

Parr CL, Keates RAB, Bryksa BC, Ogawa M, Yada RY. (2007). The structure and function of Saccharomyces cerevisiae proteinase A. Yeast 24: 467-480.

Perkins J, Kohl M. (2011). ReadqPCR: Read qPCR data. Available at http://www.bioconductor.org/packages/ 2.14/bioc/html/ReadqPCR.html.

Pinheiro J, Bates D, DebRoy S, Sarkar D, Core Team. R. (2013). nlme: Linear and Nonlinear Mixed Effects Models. Available at http://cran.r-project.org/web/ packages/nlme/index.html.

Pinto-Tomás AA, Anderson MA, Suen G, Stevenson DM, Chu FST, Cleland WW et al. (2009). Symbiotic nitrogen fixation in the fungus gardens of leaf-cutter ants. Science 326: 1120-1123.

Poulsen M, Boomsma JJ. (2005). Mutualistic fungi control crop diversity in fungus-growing ants. Science 307: 741-744.

Queller DC, Strassmann JE. (2009). Beyond society: the evolution of organismality. Philos T Roy Soc B 364: 3143-3155.

R Core Team. (2013). R: A language and environment for statistical computing. Available at http://cran.r-project. org/.

Rauscher M, Mendgen K, Deising H. (1995). Extracellular proteases of the rust fungus Uromyces viciae-fabae. Exp Mycol 19: 26-34.

Rawlings ND, Barrett AJ, Bateman A. (2012). MEROPS: the database of proteolytic enzymes, their substrates and inhibitors. Nucleic Acids Res 40: D343-D350.
Rønhede S, Boomsma JJ, Rosendahl S. (2004). Fungal enzymes transferred by leaf-cutting ants in their fungus gardens. Mycol Res 108: 101-106.

Sarath G, Zeece MG, Penheiter AR. (2001). Protease assay methods. In Beynon R, Bond JS (eds). Proteolytic Enzymes: A Practical Approach. Oxford University Press: Oxford, pp 45-76.

Schaller A. (2012). Plant Subtilisins. In Rawlings ND, Salvesen GS (eds). Handbook of Proteolytic Enzymes. Ch 717. Academic Press: New York, pp 3247-3254.

Schaller A, Stintzi A, Graff L. (2012). Subtilases-versatile tools for protein turnover, plant development, and interactions with the environment. Physiol Plantarum 145: 52-66.

Schiøtt M, De Fine Licht HH, Lange L, Boomsma JJ. (2008). Towards a molecular understanding of symbiont function: identification of a fungal gene for the degradation of xylan in the fungus gardens of leafcutting ants. BMC Microbiol 8: 40.

Schiøtt M, Rogowska-Wrzesinska A, Roepstorff P, Boomsma JJ. (2010). Leaf-cutting ant fungi produce cell wall degrading pectinase complexes reminiscent of phytopathogenic fungi. BMC Biol 8: 156.

Schultz TR, Brady SG. (2008). Major evolutionary transitions in ant agriculture. Proc Natl Acad Sci USA 105: 5435-5440.

Semenova TA, Hughes DP, Boomsma JJ, Schiøtt M. (2011). Evolutionary patterns of proteinase activity in attine ant fungus gardens. BMC Microbiol 11: 15.

Sreedhar L, Kobayashi DY, Bunting TE, Hillman BI, Belanger FC. (1999). Fungal proteinase expression in the interaction of the plant pathogen Magnaporthe poae with its host. Gene 235: 121-129.

St Leger RJ, Joshi L, Roberts DW. (1997). Adaptation of proteases and carbohydrases of saprophytic, phytopathogenic and entomopathogenic fungi to the requirements of their ecological niches. Microbiol-Sgm 143: 1983-1992.

Villesen P, Murakami T, Schultz TR, Boomsma JJ. (2002). Identifying the transition between single and multiple mating of queens in fungus-growing ants. Proc Biol Sci 269: 1541-1548.

Weber NA. (1966). Fungus-growing ants. Science 153: 587-604.

Xia Y. (2004). Proteases in pathogenesis and plant defence. Cell Microbiol 6: 905-913.

Supplementary Information accompanies this paper on The ISME Journal website (http://www.nature.com/ismej) 